\begin{tabular}{|c|c|c|} 
INTERNATIONAL JOURNAL OF \\
ORGANANIZATIONAL \\
IEADESHHIP
\end{tabular}

\title{
A Responsible Leadership Dimensional Framework Model
}

\author{
Safaa Shaaban
}

Department of Business Administration, British University in Egypt, Egypt, BUE

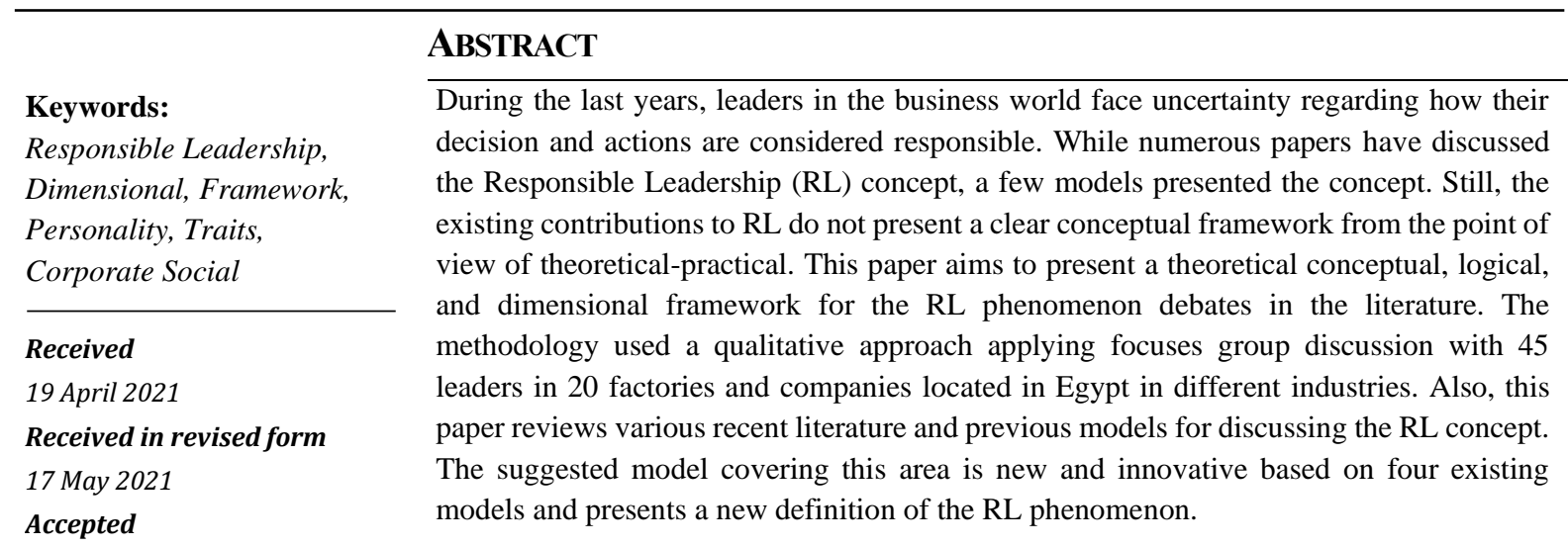

18 May 2021

*Correspondence:

Safaa.Shaban@bue.edu.eg

CCIKD Publishing

There is an increasing amount of research being published on sustainability and Corporate Social Responsibility (CSR). The concept of Responsible Leadership (RL) has become one of the growing interests in business research. Voegtlin (2015) stresses that there is an important foundation for much of the subsequent work recommended by the RL concept for further research in the last few years. The latest research perspective is to fill in research gaps and suggest attendant future directions for the field of RL. Miska and Mendenhall (2018) recommend that, based on their research and observation, two notable developments should be considered for future RL research in this area, as follows: firstly, a shift from a micro-level toward multiple levels of analysis of the RL concept, and secondly, the need to focus on both 
antecedents and outcomes of RL and to consider the phenomenon as a process rather than a state (Waldman \& Balven, 2014). Also, Dinh et al. (2014) suggest that there is a need to compare trends in the broader leadership literature. In 2015, the European Group for Organizational Studies Annual Meeting devoted an entire sub-theme to the RL (Pless \& Voegtlin, 2015). Although there have been many attempts to cover the concept of the RL, Galvin (2008) and Pless and Maak (2011) stress that there is a need to address the issues of definition and give more focus to the conceptualized framework of the RL. They suggest that it would be helpful to have scales and constructs for testing (Pless \& Maak, 2011).

The RL is known for its comprehensive approaches, which include matching various diverse elements and levels such as an individual, an organization, and a community (Shaaban \& Shehata, 2019), while Bergsteiner and Avery (2011) mention that it includes different elements such as people, organisations, leaders and followers, effectiveness, and environment. Shaaban (2020) examined and concluded in her study that responsible employees result from RL that leads to sustainable leadership.

Although the RL concept has recently attracted more research investigation and attention (Shi \&Ye 2016), literature has failed to present a systematic clear description of the main thoughts, concepts, and theoretical framework approaches underlying the research. There is no organized and systematic framework with a scale to measure it. All the potential limited studies before were presenting a suggested model that has not been examined, which has been caused a scattered in the knowledge on the RL field through many publications. Studying the existing information in the RL field will allow understanding of the key theoretical methods and themes and identify the literature gaps and key prospects for further advancement. This study participates and aims to block this research gap by examining the objective of the RL field. This paper seeks 1) to present a full image and framework for dimensions of the RL and 2) to participate in shaping the image of RL that has previously been examined, tested, and presented in the literature.

\section{Literature Review}

Of the initial studies on the concept of RL belong to Maak and Pless (2006). They defined RL as "a relational and ethical phenomenon, which occurs in social processes of interaction with those who affect or are affected by leadership and have a stake in the purpose and vision of the leadership relationship"'(Maak \& Pless, 2006, p. 32). So looking from wide view to the RL concept and early syage, the relationship between leaders and followers should be considered from contemporary view of leaders and stakeholders. To place more focus on the leaders' responsibilities in relation to several stakeholder clusters, they suggested that these relationships are central to leadership, such as building and cultivating.

There is a common understanding among the world of researchers related to RL that specifies that "Responsible Leadership responds to both existing gaps in leadership theory and the practical challenges facing leadership" (Pless \& Maak, 2011). In relation to the word "responsible', Pless and Maak (2011) interpret responsibility matters including accountability, appropriate moral decision-making, and trust. Also, regarding the concerns of others, they question for what and to whom leaders are responsible? (Pless \& Maak, 2011). 
At a stakeholder theory level, with a focus on ethics, Freeman et al. (2006) note the different perspectives and definitions of RL as "leadership in the context of contemporary stakeholder theory" (p.23 ). Bass and Steidlmeirer (1999) had previously defined RL as a "social-relational and ethical phenomenon, which occurs in social processes of interaction" (p. 16 ).

Waldman and Galvin (2018) point out that there is a lack of existing leadership theory related to the absence of the purpose of responsibility from the established explicit descriptors of leadership. However, in charismatic, transformational, authentic, participative, spiritual and ethical, servant, shared leadership, it is clear that this element is at the heart of what effective leadership is all about (Waldman \& Galvin, 2008).

Consequently, we are attempting to raise the discussion of current leadership theories to state the relevant leadership challenges and incidents that face different big businesses worldwide. These challenges and incidents cause and raise the continuing debate related to corporate-level responsibility, followed by a "critical academic debate about the impact of greed and reckless self-interest in managerial decision-making” (Pless \& Maak, 2011, p. 64 ).

The literature reveals that the bad management concept was destroying good management practice (Ghoshal, 2005 as cited in Pless \& Maak, 2011) and spoke about the need for managers, not MBAs (Mintzberg, 2004), that is, professionals with higher aims and not just hired hands (Khurana, 2007). Furthermore, a call went out for "Responsible Global Leadership"' from the European Foundation of Management Development, leading to the emergence of The Principles for Responsible Management Education (PRME), an educational offshoot of the UN Global Compact that seeks to incorporate the Compact's ten principles into the curricula of business schools worldwide (Pless \& Maak, 2011). There is a strong drive in the literature toward identifying the reform of irresponsible leadership, especially after the global economic crisis of 2008 that leadership was as one of its primary causes. To solve this primary cause, a long-term endeavor toward a new global leadership approach needs to consider individual and systemic stages toward the effective. Sachs claims in a recent book that "A society of markets, laws, and elections is not enough if the rich and powerful fail to behave with respect, honesty, and compassion toward the rest of society and toward the world.... Without restoring an ethos of social responsibility, there can be no meaningful and sustained economic recovery.' (2003, p. 27). The concept of RL is not limited to an ethical issue (Brown \& Trevin'o, 2006). RL levels from the changes in and new requests of different stakeholders in the business contexts (Maak \& Pless, 2006; Waldman \& Galvin, 2008).

Most of the literature on RL models considers the concept as various and multilevel, filling the gaps in existing leadership theories and frameworks. The RL concept is evident in highprofile scandals on three levels - the individual, the organizational, and the systemic - and increasingly targets new and emerging social, ethical, and environmental challenges in the business world. As a result, tre is a high demand for more research on the RL concept and the need to feed the literature with more research and clarity relating to the concept (Miska \& Mendenhall, 2018).

Business practice has a distinct (as opposed to distinguished?) interest in developing responsible leadership and boosting new generations of responsible leaders. Therefore, academics should develop and construct a clear understanding of the origins and outcomes of 
RL as a multilevel leadership theory. Thus, the paper's main objective is to develop and build a conceptual framework for RL.

\section{RL from other Leadership Approaches}

Different studies and researchers have distinguished RL from other leadership approaches. (Pless \& Maak, 2011) Pless and Maak (2011) have discussed and distinguished RL from other values-centered leadership theories like servant leadership presented by Greenleaf (2002), ethical leadership presented by Brown and Trevin'o (2006), authentic leadership presented by Luthans and Avolio (2003), and Gardner, Avolio, and Walumbwa (2005); transformational leadership presented by both Bass and Avolio (1995) and Shaaban (2018).

Pless and Maak (2006) argue that the main difference between these leadership theories and $\mathrm{RL}$ is that it focuses on sustainable values and positive changes, environmentally and socially. In addition, RL, with its focus on stakeholders on two levels, within and outside organizations, differentiates it from other leadership theories. Maak and Pless (2006) have described RL as being distinct from other leadership approaches that often focus on followers residing solely within the organization. Miska and Mendenhall (2018) sum up these differences and overlaps with other leadership approaches. One of the key features of these leadership approaches is the focus on hierarchies inside the organization and non-positional leadership among teams (Pearce \& Sims, 2011). The main point of these early leadership theories is to focus on the interdependencies and procedures among team members and with particular respect to a hierarchies' perspectives. There appears to be no clear target of these leadership perspectives related to social and environmental causes that link to a sustainable value within the organization (Pearce \& Conger, 2003). RL is reflected as an "umbrella concept to rethink the concept of leadership in the context of stakeholder theory" (Gond et al., 2011, p. 27). As a need for normative foundations, the focus of RL research is on social and environmental issues. The debates in the field are long-standing discussions and arguments related to the central responsibilities of businesses. Since its beginning in the 1950s (Carroll, 1999), the CSR concept has been developed until the current tendency to CR with sustainability assimilation (Carrol, 2015; Carroll \& Buchholtz, 2014; Van Marrewijk, 2003). In this concept, RL research and study is interweaved with the CSR and sustainability areas developments.

The RL concept is different from other theories in leadership as it is argued that it focuses more on different dimensions of leaders and followers. It also focuses on the culture, environment, followership, leaders, regulation, and community, providing a broader concept rather than a personal individual concept.

\section{An Analysis of Previous Theory}

The suggested RL framework in this paper is based on reviewing the following four models: The Multiple levels model of RL, developed by Miska and Mendenhall (2018), this model drawings various levels of analysis to present the RL model, with a focus on four levels, which are: a) Micro Level, which emphases on individual leaders in a business field, b) Meso Level, with a focus on groups and corporate strategy within an organizational level, c) Macro Level that emphases on culture, organizations and society, and d) Cross Level, that emphases on numerous relationships and connections between and among levels of analysis. 
The Miska, Hilbe, and Mayer's (2014) model developed an RL research-based model on three comprehensive theoretical perspectives for viewing RL concepts. This view that has three main dimensions been reviewed by other researchers are (a) stakeholder views (Maak and Pless, 2006; Stahl, Pless, \& Maak, 2013), which build on the theory of stakeholder perspective (Freeman et al. 2006; Hill \& Jones, 1992) and the conceptual framework of RL based on a broad array of different stakeholders and focuses on relational and ethical thoughtful; (b) Agent views (Friedman \& Miles, 2002) that build on the assumption which considered business leaders' performance as owners of a business, through to the individuals they are mostly responsible for (Jensen \& Meckling, 1978; Ross, 1973), and (c) Converging views (Porter \& kramer, 2006; Waldman \& Galvin, 2008; Waldman \& Siegel, 2008) that attempt to merge stakeholder and agent perspectives along with the logic of 'doing well by doing good', which a lot of literature mentions to as good management. This explanation related to RL attempts to merge economic, environmental, and social responsibilities as part of the strategic view. A clear essential commonality, important in the three levels, is the assumption that managers have the freedom of decision in their work roles (Carrol, 2015; Shaaban, 2020).

Pless, Maak, and Waldman (2012) have developed a model of RL which outlines four main approaches to the RL phenomenon based on the scope of constituent groups which considered what managers must focus on in their organizations, as well as the accountability of managers toward other shareholders and the owners of businesses. Based on their research, they developed four different orientation approaches, which are those of: (a) Traditional economists that focus on short-term economic value emphases and the orientations of shareholders; (b) Opportunity seekers, that focuses on the engagement in CR activities for instrumental reasons; (c) Integrators, who focus on seeing profit as a result of socially responsible business; and the last one; (d) Idealists that hold a broader perspective on their business responsibilities (including social and environmental challenges), often embedded and associated with strong ethical, spiritual and religious considerations.

De Bettignies (2014) developed five dimensions of RL, where his model depended on a practical level of working over many years with many business leaders. These comprise, Awareness, Vision, Imagination, Responsibility, and Action, and in each dimension, three levels focus variously on individual, organizational and social levels.

Accordingly, almost all of the models that have been developed so far in the literature focus on the broad area of CSR, that is followership and stakeholder's evaluation of the leadership. However, these models have missed one main point: the personality traits and characteristics of the leadership and leaders who implement this leadership approach. Furthermore, the conflict between organizational culture and national or international culture and the business trends and ethics is significant. To cover the shortfalls in the previous models, the following model (Figure 1) suggests a new theoretical framework for RL: 


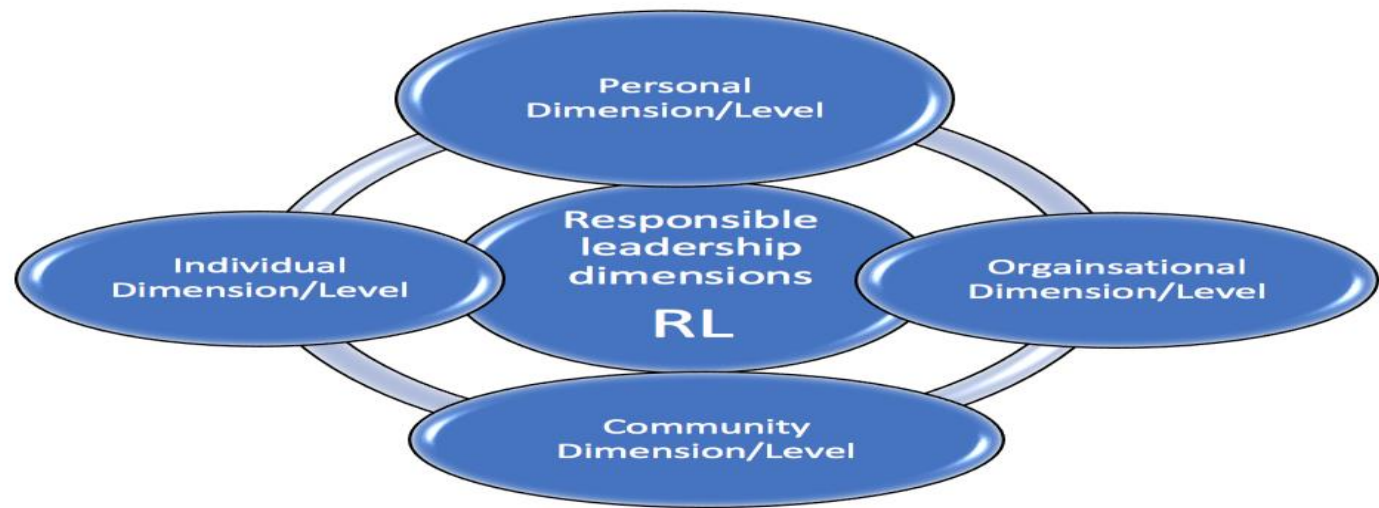

Figure 1. Responsible Leadership dimensions/ level suggested by the author.

\section{Methodology}

This study used a qualitative method of research design.

Qualitative approach and study group. The main criteria in identifying the 45 participant leaders were that they were between the ages of 30 to 45 years, middle management, and included both female and male genders in the Egyptian companies. The majority of the sample were also identified as future leaders in the selected companies. The participants were divided into three groups, each taking one day for a workshop and working closely in a focus group with one person leading the discussion. The four models presented in the literature that identified dimensions of RL were shown to the participants, and they were asked to identify the main dimensions from their perspective. They were also asked about aspects that were not considered in the other models previously. Table 1 shows the distribution of the focus group discussion vital dimensions for RL.

Table 1

The Focus Group Discussion

\begin{tabular}{|c|c|c|c|c|c|}
\hline $\begin{array}{l}\text { Focus group } \\
\text { number }\end{array}$ & $\begin{array}{l}\text { Company } \\
\text { Represented }\end{array}$ & Topics for In-Depth discussion & $\begin{array}{l}\text { Researchers } \\
\text { represented }\end{array}$ & $\begin{array}{l}\text { Face to Face/ } \\
\text { online interview }\end{array}$ & $\begin{array}{c}\text { Number of } \\
\text { participants }\end{array}$ \\
\hline Group (1) & EgyptAir company & \multirow{3}{*}{$\begin{array}{l}\text { 1- The RL concept and the parameters } \\
\text { of its dimension from the literature } \\
\text { 2- Collection of participant } \\
\text { expectations about what they think } \\
\text { the best framework should be, } \\
\text { including suggestions and how to } \\
\text { measure it }\end{array}$} & \multirow[t]{3}{*}{$\begin{array}{l}\text { Authors of } \\
\text { this paper }\end{array}$} & Face to Face & 15 \\
\hline Group (2) & $\begin{array}{l}\text { stale steal Helwan/ } \\
\text { Maddie }\end{array}$ & & & Face to Face & 15 \\
\hline Group (3) & $\begin{array}{l}\text { Alexandria/ } \\
\text { electronic and } \\
\text { renewable energy } \\
\text { factories }\end{array}$ & & & Face to Face & 15 \\
\hline $\begin{array}{l}\text { Group (1), (2) } \\
\&(3)\end{array}$ & $\begin{array}{l}\text { All companies } \\
\text { together }\end{array}$ & $\begin{array}{l}\text { 3-Presentation of the final framework with } \\
\text { dimensions/ levels, the way will be } \\
\text { measured, and its scale }\end{array}$ & $\begin{array}{l}\text { Authors of } \\
\text { this paper }\end{array}$ & Face to Face & 45 \\
\hline
\end{tabular}

Qualitative data collection approaches. The researchers used a semi-structured questionnaire to investigate the matter in-depth and comprehend from leaders and followers who participated in this study the main component of responsible leadership in realty. In the first part, the interview form comprised a workshop to explain the previous models and make sure that people understand these models that were developed previously and could discuss the applicability of 
this model to their industry and identify the missing parts in their groups in the previous models. The workshop was run in Arabic, as the background language of these industries participated in the study.

\section{The Suggested Conceptual Framework}

RL as an evolving leadership style effectively compensated for the inadequacies of traditional leadership formulae and is of substantial significance to enhancing corporate reputation and maintaining the sustainable development of enterprises and society (Voegtlin, Patzer, \& Scherer, 2012). This model is different from other leadership styles because it focuses more on building the responsibility on the three levels as a responsible employee, the responsible organisation, and the responsible community.

Based on the statistical results and discussions from the focus group with all of the 45 participants in the qualitative approach, it was agreed that the most suitable definition for RL is as follows:

" $R L$ is a dimensional approach, including different levels which are measured by different variables targeting the behaviors outside and inside the organization, behaviors, and actions to improve the existing theories of the leadership, personal, individual, organizational, and the community dimensions, which all involve ethical, environmental, reflexivity and sustainability perspectives".

This study suggests the dimensional framework in mapping by levels, including variables, that establish the RL four levels should be tested and applied by leaders according to the following:

(1) Personal Dimension, one which focuses on the personality traits and behavior level of individual leaders; (2) Individual Dimension, one focuses on individual or followers who interact and react to responsible leaders; (3) Organizational Dimension, one with a focus on organizational context, groups, and corporate strategy; and (4) Community Dimension, one with a focus on CSR, institutions, culture, and society. 
Table 2

The Dimensions Suggested and Scale to be used in the Respondent Sample

\begin{tabular}{|c|c|c|c|}
\hline Dimensions/ Levels & Concept of dimensions & Variables included & Measured by whom \\
\hline $\begin{array}{l}\text { Personal Dimension } \\
\text { Levels: } \\
\text { personality traits, ethical, } \\
\text { sustainability perspective, } \\
\text { environment oriented } \\
\text { personality traits, ethical, } \\
\text { Leaders values, ethical, } \\
\text { motivations, characteristics, } \\
\text { and achievements }\end{array}$ & $\begin{array}{l}\text { Leaders values, personality/qualities, } \\
\text { ethical, motivations, characteristics, } \\
\text { history, etc..., mostly from a } \\
\text { subjective, normative perspective. } \\
\text { Individual' different RL orientations } \\
\text { and attendant qualities and } \\
\text { competencies in view of different } \\
\text { approaches to RL }\end{array}$ & $\begin{array}{l}\text { Personality traits/ } \\
\text { Commitment }\end{array}$ & $\begin{array}{l}\text { Personality trait scale developed } \\
\text { by } \\
\text { Chittaranjan, Blom, \& Gatica- } \\
\text { perez (2013) } \\
\text { Commitment scale developed by } \\
\text { Mowday, Streers, \& Porter (1979) }\end{array}$ \\
\hline $\begin{array}{l}\text { Individual Dimension } \\
\text { Levels: } \\
\text { follower's evaluation } \\
\text { followers' perspective, } \mathbf{3 6 0} \\
\text { degree toward RL ) }\end{array}$ & $\begin{array}{l}\text { Follower reaction and interaction } \\
\text { toward RL Best personality can fit } \\
\text { with this characteristic. }\end{array}$ & Responsibly & $\begin{array}{l}\text { Responsibility scale developed by } \\
\text { Voegtlin (2011) Qualitative } \\
\text { approach to measure the } \\
\text { leadership }\end{array}$ \\
\hline $\begin{array}{l}\text { Organisational Dimension } \\
\text { Levels: } \\
\text { organizational culture, } \\
\text { Environment and suitability, } \\
\text { groups, and corporate } \\
\text { strategy, sustainable } \\
\text { leadership }\end{array}$ & $\begin{array}{l}\text { Connections between RL and other } \\
\text { related organisational features such as } \\
\text { responsible management corporate } \\
\text { governance, leadership, development. } \\
\text { The effects of RL and its difference } \\
\text { from traditional leadership } \\
\text { perspectives on companies' CSR } \\
\text { performance }\end{array}$ & $\begin{array}{l}\text { Organisation Culture } \\
(\mathrm{OC})\end{array}$ & $\begin{array}{l}\text { Organisational Culture by } \\
\text { O’Reilly, Chatman, \& Caldwell } \\
\text { (1991). }\end{array}$ \\
\hline $\begin{array}{l}\text { Community Dimension } \\
\text { Levels: } \\
\text { (CSR, institutions, } \\
\text { leadership orientation } \\
\text { culture, and society) }\end{array}$ & $\begin{array}{l}\text { The mission of the RL in reviewing the } \\
\text { dynamic of changing within } \\
\text { institutional environments with } \\
\text { explanation of addressing global } \\
\text { problems from conceptual } \\
\text { perspectives. Supporting this with } \\
\text { Empirical, comparative research on the } \\
\text { impact of institutional and cultural } \\
\text { effects on the conception framework } \\
\text { and the understanding of Responsible } \\
\text { Leadership }\end{array}$ & CSR & $\begin{array}{l}\text { CSR scale developed by } \\
\text { D'Aprile \& Talo (2014) }\end{array}$ \\
\hline
\end{tabular}

\section{Leaders Personal Dimension}

This level is related to the personality traits and ethical and behaviour levels of individual leaders. Leaders' values, personality/qualities, ethical motivations, characteristics, achievements, sustainability perspective, environment-oriented, etc., are mostly viewed from an individual normative perspective. The characteristics of RL's soft skills and personality traits include honesty, integrity, taking a long-term perspective, being open-minded, empathetic, respectful of others, and in the service of others. Judge et al. (2002) gathered the outcomes of studying 222 correlations focused on 73 studies of leadership performance and personality. The level of ethics is based on values-based judgements, building the relationship between leaders and stakeholders on ethical principles-driven; the relationship is connected through a shared sense of meaning. It raises individuals to the highest motivation and commitment levels for achieving social change and sustainable values design (Pless, 2007). Han, Wang, and Yan in (2019) state that responsible leadership increases individuals' independent environment motivation, which often engages where actions are consistent with their inside them.

On the level of personality and the relationship between leaders applying the RL approach in their organisations, Pless (2007) has further noted that a values-based and thoroughgoing ethical fundamental principles-driven relationship between stakeholders and leaders are associated with a common sense of purpose and implication, which they promoted one another 
to advanced levels of commitment to achieve social change and maintainable values. Leaders applying this RL style have to encourage themselves and their followers to build their resilience (Shaaban \& Shehata, 2019). Accordingly, the variables included in RL are a combination of personality traits, ethical leaders' values, motivations, characteristics, and achievements.

\section{The Dimension of the Followers' Perspective}

This level is related to the individual or followers' interactions and reactions to responsible leaders. It focuses on followers' reactions and interactions toward RL, in which personality can best fit this characteristic. Variables included are followers' evaluation, followers' perspective, and 360 degrees toward RL. Shaaban (2020) shows that responsible leadership sets the environmental base for the responsible employee; she also demonstrated that to have a responsible employee, we should have responsible leadership, and both, in turn, will lead to sustainability (Shaaban 2020).

At the level of followers, when leaders apply the RL approach in their organisation, the leaders in our sample organisations communicate with followers and set the system to translate the concept of responsibility. Pless and Maak (2011) pointed out that "responsible (global) leadership needs to be approached on both an individual and systemic level to be effective" (p. 23). The RL indicates a range of mindsets, a spectrum from low to high levels, depending on how the concept of leadership is considered, whether individualized or socialized (Waldman \& Galvin, 2008). Other authors such as Doh and Quigley (2014)have examined key RL phenomena as value-centered, relational, and one that intends to produce a positive outcome for followers who are considered one of the stakeholders. As a further contextual factor, Doh and Quigley (2014) and Gond et al. (2011) noted that RL can be characterized with styles of strategy-making and a focus on future objectives. The RL is also characterized and defined by Uhl-Bien (2006, p. 25) as the "great man" or the transformative and charismatic leader, something geared to the approach of relational leadership.

\section{Organizational Level}

This level mainly focuses on the organizational, group perspective, and corporate strategical level. The connections between RL and other related organizational features include responsible management, leadership, corporate governance, development, and the effects of RL and its distinction from the perspectives of traditional leadership on CR performance of companies. Variables included are organizational culture, leadership orientation, groups, corporate strategy, and sustainable leadership. In the light of the previous arguement culture is considered one of the main support of RL when leaders intened to apply the concept. Researchers have identified that the processes, practices, culture may promote the organization level and policies of organizational cultivated by its leaders (Cameron, 2010; Dutton \& Sonenshein, 2007). LaRocca (2011) supported the concept of the internal system within the organization and argued that RL is the "theory that defines followers as broad constituencies that are both internal (direct reports, peers, and supervisors) and external (community members, clients and customers, business partners, and environmental groups) to the organization" (p. 13). 


\section{Community Level}

This level is concerned with CSR, institutions, culture, and society. The mission of the RL is in reviewing the dynamics of change within institutional environments and with an explanation that addresses global problems from conceptual perspectives. Variables included are CSR, institutions, culture, and society that all support this suggestion. Considering the community and CSR levels that translated the leader's relationship with stakeholders, RL is distinct from other leadership styles in that the RL approach considers an RL leader as one who provides a lead in stakeholder relationships, whereas an earlier style of leadership was to be a follower's leader. Voegtlin, Patzer, and Scherer (2012) emphasized certain differences in behavioral approach. For instance, RL is rationally built on discourse ethics and considered democracy, while ethical leadership and authentic leadership do not have any clear logical basics.

\section{Discussion and Conclusion}

RL has increased and gained substantial traction in the academic world of management that discourse and has become the main topic in contemporary issues in management leadership (Miska, Hilbe, \& Mayer, 2014). Moreover, the contemporary business settings have also triggered a need for RL as globalization continues to confront organizations with a demand for a larger responsibility by leaders to realize better the management of stakeholders. Furthermore, RL has become an essential environment for organizational existence and success in investors' governance. Recently, business leaders are held responsible outside the economic domains, and their responsibilities spread out to different dimensions such as followers, organisation, community social, and environmental scopes (Baranova \& Meadows, 2017).

The main finding of this study results from the qualitative approaches that confirmed that the main dimensions for responsible leadership are Personal, Followers, Organizational, and Community dimensions.

While no combining RL definition has yet to appear, there is unclear acceptance among researchers that the collaboration with stakeholders constitutes an RL significant part (Doh \& Quigley, 2014; Pless \& Maak, 2011; oegtlin, Patzer, \& Scherer, 2012).

This study has presented a framework for RL based on a qualitative study from the perspective of different leaders and future leaders located in Egypt in different organisations and working in business sectors. Based on this study fininding, following dimentioned are recomeded as follows:

Practical Implications: The study results have indicated several practical implications. First, the significant connection between RL and other variables found in organisational culture was supported by an empirical study comparative research on the impact of institutional and cultural effects on the conceptual framework and the understanding of RL (Grovin \& LaRocca, 2011) and CSR. Second, significant relationships were found between the four RL variables: personality, commitment, responsibility, orgainsational culture, and CSR. Third, this study seeks to add to the body of literature concerning RL's relation to the other variables mentioned above. Finally, this research has taken into consideration these variables and their impact and correlation on RL.

Theoretical implications: Firstly, nevertheless of the national variances, the leadership, and dimensions and variables, relationships are maintained within the Egyptian setting. Secondly, 
the significant consequences found are the perceived ones of RL, Interactional and distributive, on the four levels dimensions of RL discussed.

Limitation: The study has different limitations. First, it only debates the target groups in a sampled group of factories located in Egypt. Also, the ideologies of the participants, age difference from 30 to 45 years, and the participants' role level reflect on their philosophies were identified based on interviews and observations in the qualitative design and were carried out within the same groups. So all the results applied for the same population of these groups in the wider industry will vary. Another limitation is that the responses in the self-reported questioners' step might not have required to clarify their point of view more accurately. Furthermore, although the author has tried to retain points of view in data collection and broadcasting, the author's philosophical perspectives on RL and its role may have affected the discussion considered limitation in this study.

Future research: The following are recommended for future research. Further research is required to examine the effectiveness of personality and the personality trait of leaders who will apply the RL as an approach within their organization. The followers' perspective needs to be considered in a future study because it is very important to have a reasonable number of followers to implement the responsible leadership direction. The orgainsational dimension above that supports this RL approach should be included in the orgainsational culture as a supportive environment to measure the extent to which this leadership approach succeeds or fails. The community dimensions should be studied further to understand how the community and organisations perceive the CSR concept and how it is linked to RL and is analyzed with the ethical dimension. A scale should be developed to measure all these dimensions from a qualitative approach.

\section{References}

Baranova, P., \& Meadows, M. (2017). Engaging with environmental stakeholders: Routes to building environmental capabilities in the context of the low carbon economy. Business Ethics: A European Review, 26(2), 112-129.

Bass, B, \& Avolio, B. (1995). MLQ multifactor leadership questionnaire for research. Mind Garden: Palo Alto, CA.

Bass, B. M., \& Steidlmeier, P. (1999). Ethics, character, and authentic transformational leadership behavior. Leadership Quarterly, 10(2), 181-217.

Bergsteiner, H, \& Avery, G. (2011). Sustainable leadership practices for enhancing business resilience and performance. Strategy and Leadership, 39(3), 5-15.

Brown, M, \&. Trevin'o, L. K. (2006). Ethical leadership: A review and future directions. The Leadership Quarterly, 17, 595616.

Cameron, K. (2010). Five keys to flourishing in trying times. Leader to Leader, 55, 45-51.

Carrol, A. (2015). Corporate social responsibility: The centerpiece of competing and complementary frameworks. Organizational Dynamics, 44(2), 87-96.

Carroll, A. B., \& Buchholtz, A. K. (2014). Business and society: Ethics, sustainability, and stakeholder management. Cengage Learning.

Chittaranjan, G., Blom, J., \& Gatica-Perez, D. (2013). Mining large-scale smartphone data for personality studies. Personal and Ubiquitous Computing, 17(3), 433-450. 
De Bettignies, H. (2014). Five Dimensions of responsible leadership. Insead Knowledge: Fontainbleu, France.

D’Aprile, G., \& Talò, C. (2014). Measuring corporate social responsibility as a psychosocial construct: A new multidimensional scale. Employee Responsibilities and Rights Journal, 26(3), 153-175.

Dinh, J. E., Lord, R. G., Gardner, W. L., Meuser, J. D., Liden, R. C., \& Hu, J. (2014). Leadership theory and research in the new millennium: Current theoretical trends and changing perspectives. The Leadership Quarterly, 25(1), 36-62.

Doh, J. P., \& Quigley, N. R. (2014). Responsible leadership and stakeholder management: Influence pathways and organizational outcomes. Academy of Management Perspectives, 28(3), 255-274.

Dutton, J. E., \& Sonenshein, S. (2007). Positive organizational scholarship. In S. Lopez \& A. Beauchamps (Eds.), Encyclopedia of positive psychology. Malden, MA: Blackwell Publishing.

Freeman, R. E., Martin, K., Parmar, B., Cording, M. P., \& Werhane, P. H. (2006). Leading through values and ethical principles. In R. Cooper \& C. Burke (Eds.), Inspiring leaders (pp. 149-174). New York: Routledge.

Friedman, L A, \& Miles, S. (2002). Developing stakeholder theory. Journal of Management Studies, 39(1), 1-21.

Gardner, W., Avolio, B., \& Walumbwa, F. (2005). Authentic leadership development: Emergent trends. In W. L. Gardner, B. J. Avolio, \& F. O. Walumbwa (Eds.), Authentic leadership theory and practice: Origins, effects and development (pp. 387-406). Oxford, UK: Elsevier Science.

Ghoshal, S. (2005). Bad management theories are destroying good management practices. Academy of Management Learning and Education, 4, 75-91.

Gond, J. P., Igalens, J., Swaen, V., \& El Akremi, A. (2011). The human resources contribution to responsible leadership: An exploration of the CSR-HR interface. In Responsible leadership (pp. 115-132). Springer, Dordrecht.

Greenleaf, R. (2002). Servant leadership: A journey into the nature of legitimate power and greatness. New York, Mahwah: NJ: Paulist Press.

Grovin, S. K., \& LaRocca, A. M. (2011). An empirical study of leader ethical values, transformational and transactional leadership, and follower attitudes toward corporate social responsibility. Journal of Business Ethics, 103(4), 511-528.

Hill, C., \& Jones, M. T. (1992). Stakeholder-agency theory. Journal of Management Studies, 29, 131-154.

Jensen, C. M., \& Meckling, W. H. (1978). Can the corporation survive? Financial Analysts Journal, 151-174.

Judge, T. A., Bono, J. E., Ilies, R., \& Gerhardt, M. W. (2002). Personality and leadership: a qualitative and quantitative review. Journal of Applied Psychology, 87(4),765-780.

Khurana, R. (2007). From higher aims to hired hands: The social transformation of American business schools and the unfulfilled promise of management as a profession. Princeton: Princeton University Press.

Luthans, F, \& Avolio, B. (2003). Authentic leadership: A positive developmental approach. In B. Koehler, K. Cameron, J. Dutton, R. E. Quinn (Eds.), Positive organizational scholarship (pp. 241-261). San Francisco.

Maak, T., \& Pless, N. M. (2006). Responsible leadership in a stakeholder society-a relational perspective. Journal of Business Ethics, 66(1), 99-115.

Maritz, R., Pretorius, M., \& Plant, K. (2011). Exploring the interface between strategy-making and responsible leadership. In Responsible Leadership (pp. 101-113). Springer, Dordrecht.

Mintzberg, H. (2004). Manager Not MBAs: A hard look at the soft practices of mangement and mangement developmet. SAn Fracisco, CA: berrett-Koehler.

Miska, C., Hilbe, C., \& Mayer, S. (2014). Reconciling different views on responsible leadership: A rationality-based approach. Journal of Business Ethics, 125(2), 349-360.

Miska, C., \& Mendenhall, M. E. (2018). Responsible leadership: A mapping of extant research and future directions. Journal of Business Ethics, 117-134.

Mowday, R. T., Steers, R. M., \& Porter, L. W. (1979). The measurement of organizational commitment. Journal of vocational behavior, 14(2), 224-247. https://doi.org/10.1016/0001-8791(79)90072-1

O'Reilly III, C. A., Chatman, J., \& Caldwell, D. F. (1991). People and organizational culture: A profile comparison approach to assessing person-organization fit. Academy of management journal, 34(3), 487-516.

Pearce, C, \& Conger, J. (2003). Shared leadership. In Reframing the hows and whys of leadership. London/New Delhi: Sage. 
Pearce, C, \& Sims, H. (2011). Shared leadership: Toward a multi-level theory of leadership. Advances in interdisciplinary studies of work teams. Advances in Interdisciplinary Studies of Work Teams, 7, 115-139.

Pless, N. M. (2007). Understanding responsible leadership: Roles identity and motivational drivers. Journal of Business Ethics, 74(4), 437-456.

Pless, N. M., \& Maak, T. (2011). Responsible leadership: Pathways to the future. In Responsible leadership (pp. 3-13). Springer, Dordrecht.

Pless, N. M., Maak, T., \& Waldman, D. A. (2012). Different approaches toward doing the right thing: Mapping the responsibility orientations of leaders. Academy of Management Perspectives, 26(4), 51-65.

Pless, N., Stahl \& Voegtlin. (2015) Responsible leadership: Addressing social, environmental and business implications of leadership. 29 April. Retreived from http://www.egosnet.org/jart/prj3/egos/main.jart?rel=de\&re

Porter, E. M., \& Kramer, M. R. (2006). Strategy and society: The link between competitive advantage and corporate social responsibility. Harvard Business Review, 78-92.

Ross, S. A. (1973). The economic theory of agency: The principal's problem. The American Economic Review, 63(2), 134139.

Sachs, J. D. (2003). Institutions don't rule: direct effects of geography on per capita income. No.w9490. National Bureau of Economic Research.

Shaaban, S. (2018). The impact of emotional intelligence on effective leadership In the Ministry of Military Production (MOMP) in Egypt. Journal of Business and Retail Management Research (JBRMR), 12(4).

Shaaban, S. (2020). The impact of Responsible Leadership (RL) on Responsible Employee (RE): The mediating role of Sustainable Leadership (SL). International Journal of Business and Management, 15(8).

Shaaban, S., \& Shehata, M. (2019). The impact of emotional intelligence on effective leadership In the Ministry of Military Production (MOMP) in Egypt. Journal of Business and Retail Management Research (JBRMR), 12(4), 124-163.

Shi, Y., \& Ye, M. L. (2016) Responsible leadership: Review and prospects. American Journal of Industrial and Business Management, 6, 877-884. http://dx.doi.org/10.4236/ajibm.2016.68083

Stahl, K. G., Pless, M. N., \& Maak, T. (2013). Responsible global leadership. In M. E. Mendenhall, J. Osland, A. Bird, R. G. Oddou, L. M. Maznevski, M. Stevens, \& K. G. Stahl global leadership: Research, practice, and development (pp. 240259). New York/London: Routledge.

Uhl-Bien, M. (2006). Relational leadership theory: Exploring the social processes of leadership and organizing. The Leadership Quarterly, 17, 654-676. http://dx.doi.org/10.1016/j.leaqua.2006.10.007

Van Marrewijk, M. (2003). Concepts and definitions of CSR and corporate sustainability: Between agency and communion. Journal of Business Ethics, 44(2-3), 95-105.

Voegtlin, C. (2015). What does it mean to be responsible? Addressing the missing responsibility dimension in ethical leadership research. Leadership, 12(5), 581-608.

Voegtlin, C., Patzer, M., \& Scherer, A. G. (2012). Responsible leadership in global business: A new approach to leadership and its multi-level outcomes. Journal of Business Ethics, 105(1), 1-16.

Voegtlin, C. (2011). Development of a scale measuring discursive responsible leadership. Journal of Business Ethics, 98, $57-73$.

Waldman, D. A., \& Balven, R. M. (2014). Responsible leadership: Theoretical issues and research directions. Academy of Management Perspectives, 28(3), 224-234.

Waldman, D. A., \& Galvin, B. M. (2008). Alternative perspectives of responsible leadership. Organizational Dynamics, 37(4), 327-341.

Waldman, D. A., \& Siegel, D. (2008). Defining the socially responsible leader. The Leadershi 


\section{Acknowledgments}

Not applicable.

\section{Disclosure Statement}

No potential conflict of interest was reported by the authors.

\section{Funding Acknowledgments}

Not applicable.

\section{Open Access}

The International Journal of Organizational Leadership publishes open access articles under the terms of the Creative Commons Attribution (CC BY) License, which permits use, distribution, and reproduction in any medium, provided the original work is properly cited. 